\title{
PEMBERDAYAAN FORUM KESEHATAN DESA (FKD) DALAM PENCAPAIAN CAKUPAN JAMBAN DI DESA JATIPURUS KECAMATAN PONCOWARNO KABUPATEN KEBUMEN TAHUN 2016
}

\author{
Rahmadi Setyo Projö), Djamaluddin Ramlan**), Lagiono ***) \\ Jurusan Kesehatan Lingkungan, Politeknik Kesehatan Kemenkes Semarang \\ Jalan Raya baturaden KM 12 Purwokerto, Indonesia
}

\begin{abstract}
Abstrak
Desa Siaga Jatipurus terbentuk sejak tahun 2007 dan cakupan kepemilikan jamban sehat permanen masih belum mengalami peningkatan yaitu baru sekitar 78,35 \%. Penelitian ini bertujuan untuk melihat upaya pemberdayaan masyarakat melalui forum kesehatan desa dalam pencapaian cakupan jamban di Desa Jatipurus Kecamatan Poncowarno Tahun 2016. Jenis penelitian ini adalah penelitian deskriptif dengan menggambarkan keadaan situasi, perbedaan situasi dan perkembangan melalui survei dengan menyebarkan kuisioner pada 40 responden untuk mengetahui persepsi masyarakat tentang kegiatan FKD dan melakukan wawancara mendalam pada anggota FKD dan petugas promosi Kesehatan. Hasil Penelitian ini menunjukkan bahwa, Kelembagaan FKD di Desa Jatipurus mempunyai legalitas dalam melaksanakan tugas dan fungsinya. Kegiatan FKD di Desa Jatipurus sudah sesuai dengan Pedoman Pelaksanaan Desa Siaga di Jawa Tengah. Responden berpersepsi FKD belum melaksanakan kegiatan terkait STBM. Cakupan jamban sehat Sebelum ada Desa Siaga sebanyak 37\%, jamban semi permanen 35,7\%, sharing 8,3\% dan buang air besar sembarangan 19\%. Dan sesudah ada desa siaga cakupan kepemilikan jamban sehat sebanyak 35,4\%, jamban semi permanen 36,1\%, sharing 6,7\% dan buang air besar sembarangan meningkat menjadi 21,6\%. Meskipun FKD sudah bekerja, tetapi cakupan jamban terkait STBM belum optimal. Simpulan dan saran menunjukkan bahwa, persentase buang air besar sembarangan mengalami peningkatan, maka diharapkan FKD dapat membuat sebuah regulasi untuk membuat efekjera yang pada akhirnya dapat mengeliminasi perilaku buang air besar sembarangan dari hasil penelitian, kepemilikan jamban sehat permanen dan jamban sehat semi permanen masih kurang, maka disarankan FKD dapat menjalin kemitraan dengan pihak ketiga untuk memberikan bantuan pembuatan jamban permanen.
\end{abstract}

Kata kunci : FKD, STBM, Jamban

\begin{abstract}
Desa SiagaJatipurus formed since 2007, coverage healthy permanent latrine ownership still has risen only about $78.35 \%$. Community empowerment through village health forum in the achievement of latrine coverage in the village of the District Jatipurus Poncowarno 2016. The method used is descriptive research by describing the state of the situation, differences in circumstances and developments through a survey by distributing questionnaires to the 40 respondents to assess public perception of FKD activities and conduct in-depth interviews on FKD members and health promotion officer. The results of this study show that, in the village of Institutional FKD Jatipurus has the legality in carrying out its duties and functions. FKD activities in the village Jatipurus are in accordance with the Guidelines prepared village in Central Java. Respondents berpersepsi FKD not carry out activities related to STBM. Scope of healthy latrines Before Alert Village as much as 37\%, 35.7\% semi-permanent latrine, sharing $8.3 \%$ and defecation $19 \%$. And when there is standby village latrine ownership healthy coverage as much as $35.4 \%, 36.1 \%$ semi-permanent latrine, sharing $6.7 \%$ and defecation increased to $21.6 \%$. Although FKD already working, but the latrine coverage related STBM not optimal. Conclusions and suggestions show that the percentage of defecation increased, it is expected FKD can make a regulation to make efekjera that could ultimately eliminate the behavior of defecation of the research results, the ownership of healthy latrines permanent and healthy latrines semi-permanent is still lacking, FKD it is advisable to enter into partnerships with third parties to provide assistance in establishing the permanent latrines.
\end{abstract}

Key word : FKD, STBM, Latrine 


\section{Pendahuluan}

Era Millenium Development Goals (MDGs) telah berakhir di tahun 2015 yang kemudian dilanjutkan dengan Sustainable Development Goals (SDGs). Ada 17 tujuan yang harus dicapai dalam SDGs, satu diantaranya adalah menjamin ketersediaan dan pengelolaan air serta sanitasi yang berkelanjutan bagi semua orang. Outcome yang diharapkan dari tujuan tersebut adalah munculnya budaya perilaku hidup bersih dan sehat terkait dengan akses terhadap sarana air bersih dan sanitasi yang layak serta mengakhiri defekasi terbuka (Rakorpop kemenkes RI,2015).

Berdasarkan laporan Join Monitoring Program (JMP) WHO/UNICEF tahun 2015, Indonesia menduduki peringkat ke 2 setelah India dalam peerilaku buang air besar sembarangan. Setidaknya ada 51 juta penduduk Indonesia yang buang air besar sembarangan. Penyebabnya menurut UNICEF Wash adalah 1) kebiasaan yang tertanam sejak kecil sehingga sulit diubah setelah dewasa, 2) tidak memiliki jamban oleh sebab ketidakmampuan untuk memiliki jamban dan 3) tidak memiliki rumah. Masih menurut UNICEF Wash, 2,4 milyar penduduk dunia tidak memiliki jamban, dan 1/8 nya atau sekitar 946 masih buang air besar di tempat terbuka, sedangkan di Indonesia 12,9\% penduduk Indonesia belum memiliki jamban.

Propinsi Jawa Tengah 9.914.885 KK, 50 $\%$ atau 4.691.516 KK sudah memiliki jamban sehat permanen dan mengalami peningkatan 1,3

$\%$ setelah adanya program STBM menjadi 5.490.762 KK. Sementara di Kabupaten Kebumen, dari 340.954 KK cakupan terhadap akses jamban sudah mengalami peningkatan dari $84,93 \%$ menjadi $87,39 \%$.

Poncowarno adalah satu dari 35 Kecamatan yang ada di Kabupaten Kebumen, data Profil Kesehatan Tahun 2015 menunjukkan bahwa angka BABS dari tahun 2013, 2014 dan 2015 mengalami peningkatan dari 42,8\% di tahun 2013 menjadi 41,2\% di tahun 2014 dan meningkat 2,5 $\%$ di tahun 2015 menjadi 43,7 \%. Meskipun demikian persentase akses ke jamban mengalami peningkatan dari 70,48 \% menjadi 76,44\%. Berikut tabel STBM di Kecamatan Poncowarno Tahun 2015.

Berbagai upaya dilakukan pemerintah untuk meningkatkan akses terhadap jamban dan mengeliminasi buang air besar sembarangan. Diantara berbagai program itu adalah STBM
(Sanitasi Total Berbasis Masyarakat), PAMSIMAS dan Desa SIAGA. Diharapkan dengan upaya upaya pemberdayaan masyarakat dapat merubah perilaku masyarakat dan meningkatkan kesadaraan akan pentingnya hidup bersih dan sehat.

Program Desa Siaga pertama kali diluncurkan di Jawa Tengah tahun 2007, Kabupaten Kebumen termasuk Kabupaten yang menjadi pilot project Desa SIAGA. Program desa siaga bertujuan agar masyarakat dapat mencegah dan mengatasi permasalahan kesehatan, bencana dan kegawat daruratan yang timbul di wilayahnya secara mandiri, sehingga masyarakat yang tinggal di desa tersebut dapat hidup dalam lingkungan yang sehat, berperilaku hidup sehat dan ada akses terhadap pelayanan keehatan yang bermutu (Dinkesprop, 2010).

Desa Jatipurus telah terbentuk kelembagaan Desa Siaga sejak tahun 2007, dan sudah mengalami satu kali reorganisasi Forum Kesehatan Desa. Berdasarkan wawancara penulis dengan bidan desa, kegiatan Desa Siaga di Desa Jatipurus cenderung aktif hal ini terlihat dari adanya dana sosial, rapat FKD dan alokasi Dana Desa untuk kegiatan Desa Siaga. Meskipun demikian, cakupan kepemilikan jamban sehat permanen masih belum mengalami peningkatan, yaitu baru sekitar 95

KK dari 384 KK (Website STBM, 2015). Sebelum terbentuk desa siaga cakupan jamban sehat di Desa Jatipurus sebanyak 87 KK dari 384 KK. Ini berarti peningkatan cakupan jamban sehat baru sekitar 1,3\% dalam kurun waktu 10 tahun. Untuk itulah melalui skripsi ini, penulis ingin mengetahui upaya Pemberdayaan Forum Kesehatan Desa dalam pencapaian cakupan jamban di Desa Jatipurus Kecamatan Poncowarno tahun 2015.

Tujuan umum dari penelitian ini adalah mengetahui Pemberdayaan Forum Kesehatan Desa dalam pencapaian cakupan jamban di Desa Jatipurus Kecamatan Poncowarno Tahun 2016. Sedangkan tujuan khususnya adalah untuk mengetahui Kelembagaan FKD di Desa Jatipurus, mengetahui Kegiatan FKD di Desa Jatipurus, mengetahui persepsi masyarakat tentang kegiatan FKD terkait STBM, mengetahui cakupan kepemilikan Jamban sebelum terbentuknya FKD, mengetahui cakupan kepemilikan jamban setelah terbentuknya FKD, mendeskripsikan peran FKD 
dalam pencapaian cakupan jamban di Desa Jatipurus

\section{Bahan dan Metode}

Metode yang digunakan dalam penelitian ini adalah metode deskriptif. Lokais penelitian di Desa Jatipurus Kecamatan Poncowarno. Objek dari penelitian ini adalah Forum Kesehatan Desa. Penelitain dilakukan dengan memberikan kuisioner pada 40 warga, wawancara mendalam dengan anggota FKD da petugas promosi kesehatan serta telaah dokumen administrasi Desa Siaga Desa Jatipurus

\section{Hasil dan Pemnahasan}

Desa Siaga Jatipurus terbentuk tahun 2007. Awal mula terbentuknya Desa Siaga di Desa Jatipurus adalah adanya program Desa Siaga di Kabupaten Kebumen dimana Desa Jatipurus termasuk satu dari lima desa di Kecamatan Poncowarno yang mendapat kesempatan pertama kali mendapat pelatihan Desa Siaga.

Sejak awal terbentuknya hingga penelitian ini dilakukan, Forum Kesehatan Desa (FKD) Desa Jatipurus sudah berganti ketua sebanyak dua kali.

FKD dipimpin oleh seorang ketua yang dibantu oleh wakil dan sekretaris untuk melaksanakan tugas harian. Sementara, pelaksana teknis kegiatan adalah seksi-seksi dalam FKD. Bidan desa masuk dalam seksi upaya kesehatan dan dibantu oleh dua orang kader kesehatan

1. Tugas Pokok dan Fungsi

Berdasarkan telaah dokumen dari buku admnisitrasi Desa Siaga, maka dapat diperoleh uraian tugas dari masing-masing seksi. Adapun uraian tugas tersebut adalah sebagaiberikut:

Tabel 4.1 Uraian Tugas Kepengurusan FKD Desa Jatipurus Tahun 2016

\begin{tabular}{lll}
\hline No & $\begin{array}{l}\text { Kedudukan } \\
\text { dalam FKD }\end{array}$ & \multicolumn{1}{c}{ Tugas } \\
\hline 1. & Ketua & $\begin{array}{l}\text { Memimpin } \\
\text { pertemuan, memnjadi } \\
\end{array}$ \\
& & $\begin{array}{l}\text { Fasilitator, Pembina } \\
\text { dan pengawas dalam } \\
\text { kegiata FKD } \\
\text { Membantu ketua FKD } \\
\text { dalam pembinaan, } \\
\text { bimbingan, fasilitasi } \\
\text { dan evaluasi tiap-tiap }\end{array}$
\end{tabular}

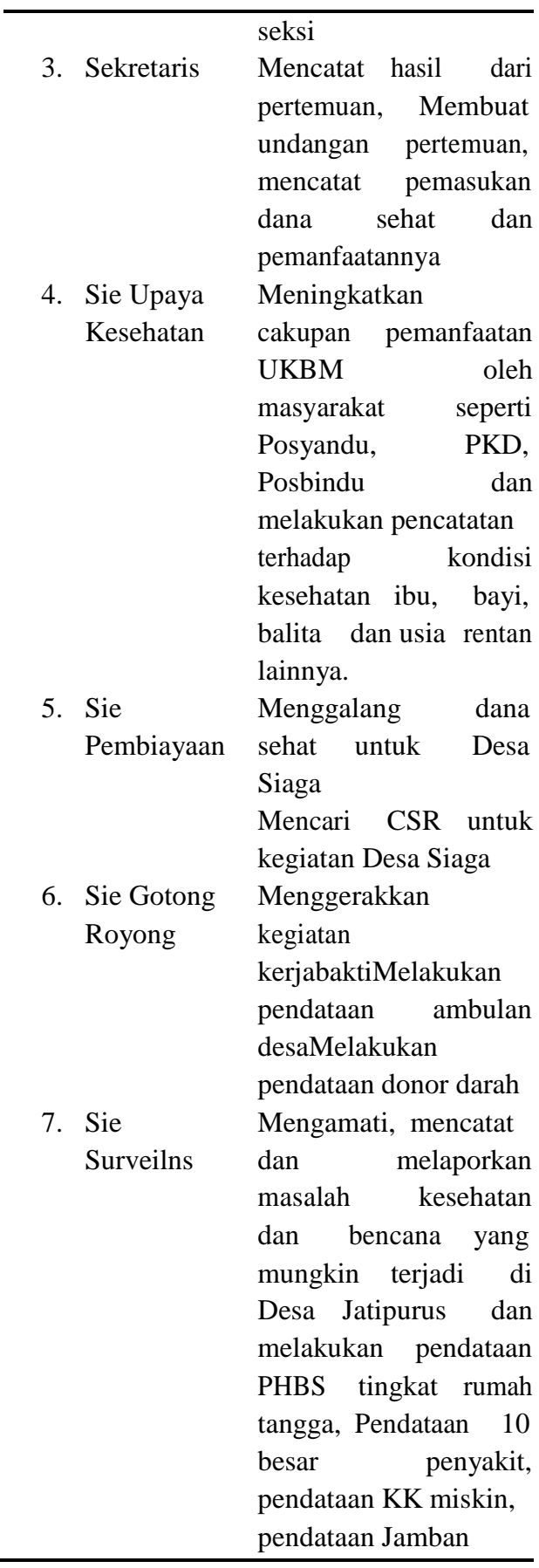

Tabel 4.1 diatas dapat diketahui bahwa FKD Desa Jatipurus sudah memiliki kelompok kegiatan yang jelas. Kegiatan yang terkait dengan STBM diantaranya adalah pendataan 10 besar penyakit, pendataan jamban, pendataan PHBS, kegiatan promotif Stop BABS dan promosi jamban sehat.

2. Kelengkapan Buku Administrasi

Tabel 4.2 Kelengkapan Administrasi

FKD Desa Jatipurus Tahun 2016 


$$
\text { Menurut }
$$

Pedoman

Pelaksanaan Desa Siaga di Jawa Tengah

\begin{tabular}{|c|c|c|c|c|}
\hline \multirow[t]{2}{*}{ NO } & \multirow{2}{*}{\multicolumn{2}{|c|}{ Buku }} & \multicolumn{2}{|c|}{ Keterangan } \\
\hline & & & Ada & Tidak \\
\hline$\overline{1 .}$ & Buku & angan & $\mathrm{V}$ & \\
\hline 2. & Buku & daftar & V & \\
\hline 3. & Buku & ulen & V & \\
\hline 4. & Buku & & V & \\
\hline 5. & SIP & & V & \\
\hline 6. & Buku & catatan & & V \\
\hline 7. & Buku & dataan & & \\
\hline 8. & Buku & kondisi & & V \\
\hline 9. & Buku & catatan & V & \\
\hline 0. & Buku & kasus & & V \\
\hline 1. & Buku & Daftar & V & \\
\hline
\end{tabular}

Buku administrasi tersebut mengacu pada Pedoman Pelaksanaan Desa Siaga di Propinsi Jawa Tengah Tahun 2016.

a. Kegiatan FKD

FKD dikatakan baik jika indikator keberhasilan dalam FKD terpenuhi, berikut adalah bentuk kegiatan FKD di Desa Jatipurus

jika dibandingkan dengan indikator keberhasilan desa siaga menurut Pedoman Pelaksanaan Desa Siaga di Jawa Tengah Tahun 2016.

Tabel 4.3 Indikator Keberhasilan Desa

Siaga di Desa Jatipurus Tahun 2016

Menurut Pedoman Desa Siaga di

Jawa Tengah

\begin{tabular}{lll}
\hline Kegiata & Indikator & Realita \\
$\mathrm{n}$ &
\end{tabular}

\begin{tabular}{lll}
\hline Polikilin & $\begin{array}{l}\text { 1. Caku } \\
\text { ik }\end{array}$ & Cakupan \\
Keseha & kesehatan & pelayanan su - \\
dah $80 \%$ \\
tan & $80 \% \quad$ Persalinan di \\
Desa & $2 . \quad$ Pema & tenaga ke - \\
& nfaatanPersali & sehatan 100\% \\
& $-\quad$ Ada upaya \\
& nan di Tenaga & deteksi dini \\
& Kese - & penyakit dan \\
& kewaspa- \\
& minimal $50 \%$ & daan kesehatan \\
& 3. Ada & lainnya \\
& upaya deteksi & Strata posyandu \\
dini penyakit & mening-
\end{tabular}

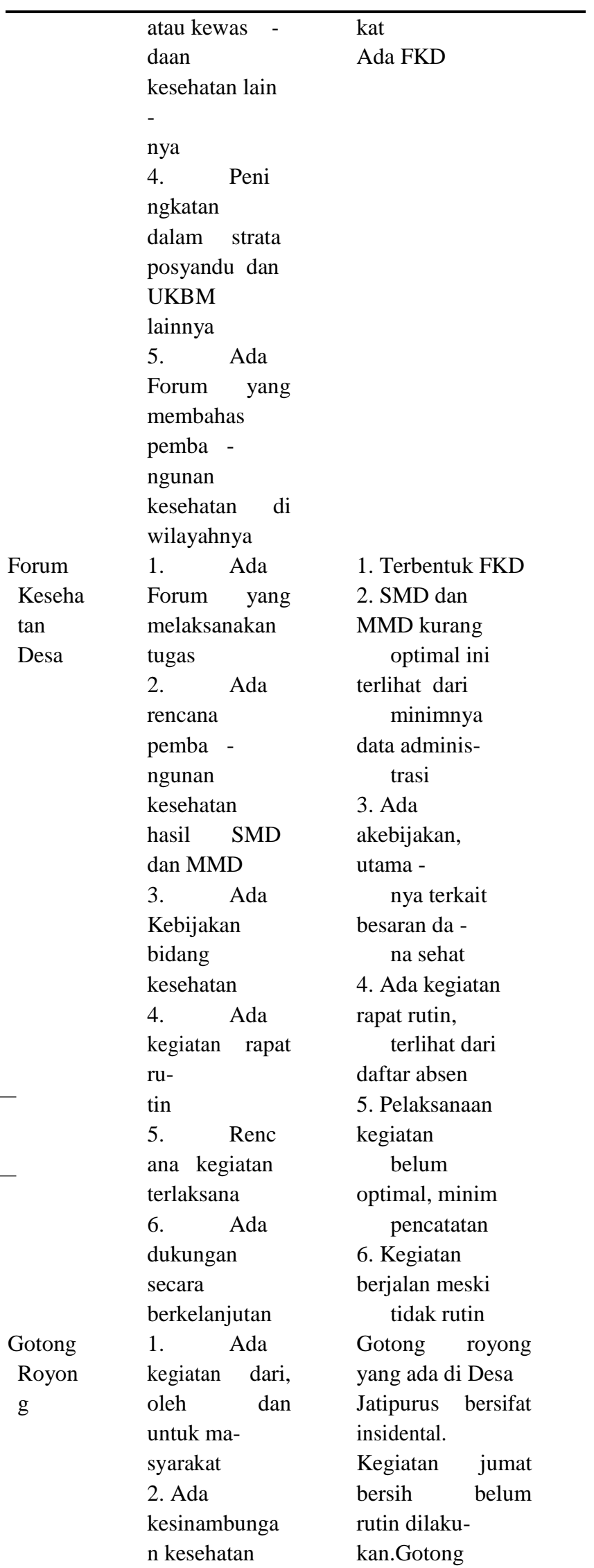




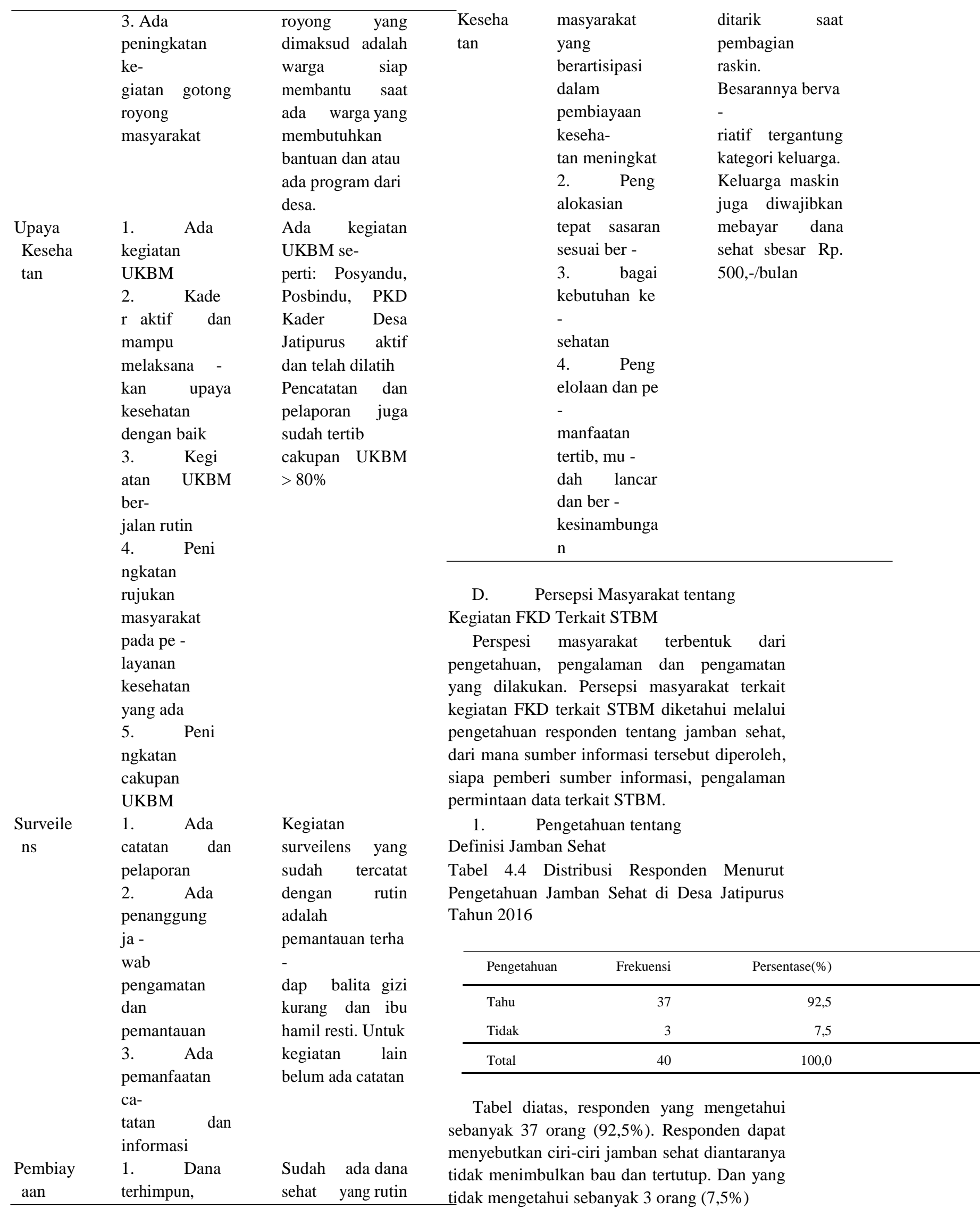


2.Sumber Informasi tentang Jamban Sehat

Tabel 4.5 Distribusi Responden Menurut

Sumber Informasi Jamban Sehat di Desa

Jatipurus Tahun 2016

\begin{tabular}{lcl}
\hline Sumber Informasi & Frrekuensi & $(\%)$ \\
\hline Tenaga Kesehatan & 29 & 72,5 \\
FKD & 8 & 20 \\
$\begin{array}{l}\text { Belum Pernah } \\
\text { Mendapat Informasi }\end{array}$ & 3 & 7,5 \\
\hline Total & 40 & 100,0 \\
\hline
\end{tabular}

Responden yang menyatakan mendapat informasi mengenai jamban sehat dari tenaga kesehatan yaitu sebanyak 29 orang (72,5\%), sisanya mengaku memperoleh informasi tentang jamban sehat dari pengurus FKD yaitu 8 orang $(20 \%)$ dan ada 3 orang $(7,5 \%)$ yang menyatakan belum pernah mendapatkan informasi tentang jamban sehat.

3. Tempat Mendapatkan Informasi

Tentang Jamban Sehat

Tabel 4.6 Distribusi Responden Menurut Tempat Mendapatkan Informasi Jamban Sehat di Desa Jatipurus Tahun 2016

\begin{tabular}{lcc}
\hline Tempat & & \\
Mendapatkan & F & $(\%)$ \\
Informasi & & \\
\hline Tempat Pelayanan & & \\
Kesehatan & 24 & 65 \\
Balai Desa & 13 & 35 \\
\hline Total & 37 & 100 \\
\hline
\end{tabular}

Responden mendapatkan informasi jamban sehat di tempat pelayanan kesehatan dalam hal ini PKD dan Posyandu sebanyak 24 orang $(65 \%)$ dan sisanya menyatakan mendapatkan informasi di balaidesa saat ada pertemuan atau ada penyuluhan.

4. Perspepsi tentang Pendataan Jamban Sehat

Tabel 4.7Distribusi Responden Menurut Persepsi Kepemilikan Jamban

2016

Sehat di Desa Jatipurus Tahun
Pernah

Berdasarkan tabel 4.11 sebagian besar responden berpersepsi sudah pernah dilakukan pendataan terkait kepemilikan jamban sehat sebesar 28 orang (70\%), sedangkan sisanya berpersepsi belum pernah dilakukan pendataan.

5. Perspesi Ada/Tidak Arisan Jamban Tabel 4.8 Distriibusi Responden Menurut Persepsi Ada/Tidak Arisan Jamban di Desa Jatipurus Tahun 2016

\begin{tabular}{lll}
\hline Persepsi Arisan Jamban & F & $(\%)$ \\
\hline Ada & 0 & 0 \\
idak & 40 & 100 \\
\hline Total & 40 & 00 \\
\hline
\end{tabular}

Berdasarkan tabel tersebut diatas, dapat kita ketaui bahwa semua responden menyatakan tidak ada arisan jamban di Desa Jatipurus sebanyak $(100 \%)$

6. Perspesi Ada/Tidak Bantuan Pembuatan Jamban Sehat

Tabel 4.9 Distribusi Responden Menurut Persepsi Ada/Tidak Bantuan Pembuatan Jamban Sehat di Desa Jatipurus Tahun 2016

Persepsi Tentang

Bantuan Jamban Sehat $\quad$ F $\quad(\%)$

$\begin{array}{lll}A d a & 14 & 35\end{array}$

\begin{tabular}{lcl} 
Tidak & 26 & 65 \\
\hline Total & 40 & 100 \\
\hline
\end{tabular}

Responden yang berpersepsi tidak ada bantuan untuk pembuatan jamban sehat dari pemerintah desa sebanyak 26 orang $(65 \%)$. Sisanya 14 orang (35\%) berpersepsi ada bantuan untuk pembuatan jamban sehat.

E. Kepemilikan Jamban

Tabel 4.10 Distribusi Responden Menurut Kepemilikan Jamban di Desa Jatipurus Tahun 2016
Kepemilikan Jamban

Frekuensi
(\%) 


\begin{tabular}{ccc}
\hline Memenuhi syarat & 34 & 85 \\
Tidak memenuhi syarat & 6 & 15 \\
\hline Total & 40 & 100 \\
\hline
\end{tabular}

Tabel 4.7 diketahui ada 34 orang (85\%) yang sudah memiliki jamban sehat sesuai standar dan ada 6 orang (15\%) yang belum memiliki jamban dan atau sudah memiliki tetapi belum sesuai standar.

F. Mengetahui Jumlah Jamban Sebelum ada Desa Siaga dan Setelah ada Desa Siaga

Tabel 4.11 Cakupan Jamban Sebelum dan Sesudah Adanya Desa Siaga di Desa Jatipurus Tahun 2006 s/d 2016 untuk ikut pembinaan. Kami juga melakukan studi banding ke Desa Mrentul yang merupakan desa percontohan Desa Siaga dari sisi pendanaan, kami juga memberikan dana stimulan untuk melakukan pertemuan di tingkat desa yang terdiri dari tahap sosialisasi desa siaga, MMD (Musyawarah Masyarakat Desa) hingga pembentukan Forum Kesehatan Desa dan Forum Kesehatan Kecamatan.

Dua tahun berselang, kegiatan ini mati suri. Banyak faktor yang menyebabkan tidak berjalannya desa siaga. Faktor internal, banyak kepala desa yang berganti, sehingga kepala desa baru merasa tidak perlu melanjutkan program kepala desa lama. Bidan desa kembali harus melakukan pendekatan terhadap pemeritahan yang baru. Faktor lain, adalah tidak adanya dana stimulan untuk kegiatan/pertemuan Desa Siaga membuat pemerintah desa enggan meluangkan waktu khusus untuk melakukan MMD dan atau

\begin{tabular}{|c|c|c|c|}
\hline \multirow{2}{*}{$\begin{array}{l}\text { Cakupan } \\
\text { Jamban }\end{array}$} & Sebelum & & Setelah \\
\hline & $\mathrm{F}$ & $\%$ & F \\
\hline
\end{tabular}

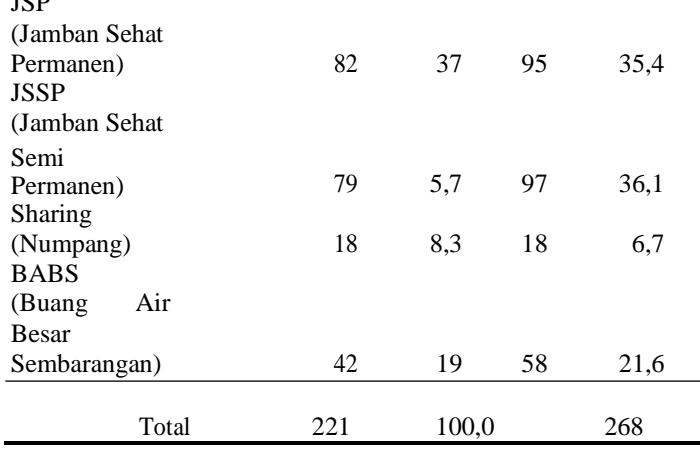

Tabel 4.14 di atas dapat kita baca bahwa, tidak ada peningkatan kepemilikan jamban sehat permanen maupun jamban sehat semi permanen. meskipun ada penurunan dijumlah sharing tetapi ada peningkatan yang signifikan pada perilaku buang air besar sembarangan. Kelompok yang sharing dapat jadi membuat jamban sehat permanen tetapi juga dapat kembali ke perilaku semula buang air besar sembarangan.

G. Mendeskripsikan peran FKD dalam pencapaian cakupan jamban di Desa Jatipurus

Desa Siaga pertamakali diperkenalkan di Kecamatan Poncowarno tahun 2007. Ada lima desa yang dijadikan pilot projek, Jatipurus salah satunya. Kami tidak hanya mengirim bidan desa untuk pelatihan desa siaga tapi juga mengirim Kepala Desa, Tokoh Masyarakat dan Kader Persenta

Jika dilinat dari indikator strata desa siaga, desa siaga di Desa Jatipurus merupakan desa siaga aktif, ini dapat di lihat dari sisi jumlah kader, fasilitas pelayanan kesehatan yang buka setiap hari, adanya UKBM dan dana sehat. Jika dilihat dari tertib administrasi, FKD di Desa Jatipurus belum secara keseluruhan mengisi kelengkapan buku admiistrasi.

Hasil penelitian dilakukan dengan melakukan wawancara mendalam dengan 17 pengurus00,0 FKD Desa Jatipurus. Wawancara mendalam dilaksanakan mulai tanggal 13 Juni sampai dengan 30 Juni 2016 di rumah masing masing informan. Metode ini dilakukan untuk menggali informasi tentang Forum Kesehatan Desa dan diharapkan jawaban yang diperoleh dapat objektif dan sesuai dengan realitas.

Wawancara mendalam dilakukan untuk menguatkan hasil penelitian kuantitatif mengenai evaluasi kegiatan FKD terkait upaya peningkatan cakupan jamban sehat di Desa Jatipurus. Diharapkan hasil dari wawancara mendalam ini dapat digunakan sebagai pembanding dari jawaban responden sekaligus jawaban dari penelitian ini. Informan dalam penelitian ini adalah semua pengurus FKD dan petugas promosi kesehatan UPTD Unit Puskesmas Poncowarno.

1. Karaterikstik Informan

Penelitian ini informan utama adalah pengurus FKD Desa Jatipurus, sedangkan informan pendukung adalah petugas promosi
( 
kesehatan selaku pendamping program Desa Siaga.Informan pendukung dalam penelitian ini adalah Petugas Promosi Kesehatan. Etika Promosi Kesehatan adalah pendamping kegiatan Desa Siaga dimana Forum Kesehatan desa bernaung, diharapkan jawaban dari petugas promosi kesehatan dapat menjadi data dukung

untuk memberkan gambaran tentang pemberdayaan Forum Kesehatan Desa dalam pencapaian cakupan jamban di Desa Jatipurus.

2. Paparan Hasil Wawancara Mendalam dengan Informan Utama

Panduan wawancara mendalam ditanyakan hal-hal yang berkaitan dengan program kerja dan upaya promotif terkait jamban sehat di Desa Jatipurus meliputi ada tidaknya rapat rutin FKD, program kerja, pendataan 10 besar penyakit, pendataan jamban sehat, rencana kerja untuk meningkatan cakupan jamban, upaya promotif terkait jamban sehat dan dana stimulan untuk jamban sehat.

\section{a. Rapat Rutin FKD}

Informan dalam penelitian ini menyatakan ada rapat rutin Forum Kesehatan Desa (FKD), masih menurut sebagian besar informan rapat rutin dilaksanakan setiap 3 (tiga) bulan sekali. Berdasarkan hasil jawaban informan, rata-rata informan menyatakan bahwa ada jadwal untuk pertemuan rutin Forum Kesehatan Desa (FKD) yaitu setiap tiga bulan sekali.

b. Program Kerja

Ketika penulis menanyakan apa saja yang dibahas dalam pertemuan tersebut adakah pembahasan terkait program kerja Forum Kesehatan Desa (FKD), maka semua informan menyatakan ada pembahasan mengenai program kerja FKD. Pendataan 10 besar PenyakitSecara teori, pendataan 10 besar penyakit rutin dilakukan setiap bulan. Hal ini bertujuan untuk mengetahui trend penyakit, sehingga Forum Kesehatan Desa mengetahui permasalahan

kesehatan yang ada di wilayah mereka.Pendataan Kepemilikan Jamban SehatPendataan kepemilikan jamban sehat merupakan salah satu langkah awal analisa situasi kesehatan di Desa Jatipurus. Analisa Situasi adalah tahapan yang harus dijalani oleh Forum Kesehatan Desa di awal tahun untuk menentukan rencana kerja. Semua informan menyatakan ada pendataan tentang kepemilikan jamban sehat. c. Program Kerja FKD Terkait Peningkatan Cakupan Jamban

Hasil wawancara mendalam, semua informan menyatakan ada program kerja untuk upaya mengurangi buang air besar sembarangan dan meningkatkan cakupan kepemilikan jamban sehat.

d. Upaya Promotif untuk Meningkatkan Cakupan Jamban

Upaya promotif untuk meningkatkan cakupan jamban, menurut informan sudah dilaksanakan. Baik secara edukatif saat pertemuan, dan bantuandana stimulasi untuk pembuatan jamban sehat.

Dua tahun berselang, kegiatan ini mati suri. Banyak faktor yang menyebabkan tidak berjalannya desa siaga. Faktor internal, banyak kepala desa yang berganti, sehingga kepala desa baru merasa tidak perlu melanjutkan program kepala desa lama. Bidan desa kembali harus melakukan pendekatan terhadap pemeritahan yang baru dan tidak adanya dana stimulan untuk kegiatan/pertemuan Desa Siaga membuat pemerintah desa enggan meluangkan waktu khusus untuk melakukan MMD dan atau hanya sekedar reorganisasi FKD.

Simpulan Kelembagaan Forum Kesehatan Desa (FKD) di Desa Jatipurus terbentuk tahun 2007, Kegiatan Forum Kesehatan Desa (FKD) di Desa Jatipurus belum memprioritaskan pencapaian cakupan jamban, tetapi masih lebih memprioritaskan pada bidang kesehatan yang

langsung berhubungan dengan
kegawatdaruratan dan sosial. Persepsi masyarakat tentang kegiatan FKD terkait STBM Jamban masih belum merupakan prioritas dalam kebutuhan hidup sehari-hari bagi masyarakat. Sebelum ada Desa Siaga cakupan kepemilikan jamban sehat sebanyak $37 \%$, jamban semi permanen $35,7 \%$, sharing $8,3 \%$ dan buang air besar sembarangan $19 \%$.Setelah ada desa siaga cakupan kepemilikan jamban sehat sebanyak $35,4 \%$, jamban semi permanen $36,1 \%$, sharing $6,7 \%$ dan buang air besar sembarangan meningkat menjadi 21,6\%. Secara umum, FKD sudah bekerja tetapi dalam upaya pencapaian cakupan jamban masih belum optimal.

1. Saran : FKD dapat membuat sebuah regulasi untuk membuat efek jera yang pada akhirnya dapat mengeliminasi perilaku buang air besar sembarangan. FKD dapat menjalin kemitraan dengan pihak ke tiga 
untuk memberikan bantuan pembuatan jamban permanen.

Ucapan terimakasih Bapak Sugiyanto, S.Pd., M.App., Sc., selaku Direktur Politeknik Kesehatan Kemenkes Semarang. Bapak Asep Tata Gunawan, SKM., M.Kes., selaku Ketua Jurusan Kesehatan Lingkungan Purwokerto. Hari Rudijanto IW, ST., M.Kes., selaku Ketua Prodi DIV Kesehatan Lingkungan Purwokerto. Bapak Dr. DJamalludinRamlan, SKM., M.Kes., selaku pembimbing I Skripsi. Bapak Lagiono, SKM., M.Kes.,selaku pembimbing II Skripsi. Kepada Dinas Kesehatan Kabupaten Kebumen yang telah membantu dalam memberikan data penelitian. Kepala UPTD Unit Puskesmas Poncowarno Kabupaten Kebumen yang telah membantu dalam memberikan data dan pelaksanaan penelitian. Kepada pihak desa dan kelembagaan Forum Kesehatan Desa (FKD) terimakasih atas ijinnya serta kerjasamanya dan yang telah memberikan ruang yang secukupnya untuk penelitian. Teman-teman yang telah banyak membantu penulis dalam menyelesaikan ini. Semua pihak yang tidak dapat penulis sebutkan satu persatu yang telah membantu

\section{Daftar Pustaka}

Aris Santjaka, 2011. Statistik untuk penelitian kesehatan 2. Nuha Medika. Yogyakarta.

Depkes RI. 1994. Desa Percontohan Kesehatan Lingkungan. Ditjen PPM dan PL. Perpustakaan AKL Depkes Purwokerto.

Depkes RI. 2007. Desa Siaga Petunjuk Teknis Penyehatan Lingkungan. Ditjen PP \& PL Direktorat Penyehatan lingkungan. Jakarta.

Depkes RI. 2010. Indonesia Sehat 2010. Perpustakaan AKL Depkes Purwokerto.Banyumas.

Depkes RI. 2002. Pedoman Teknis Penilaian Rumah Sehat. Ditjen PPM dan PL. Jakarta.

Dinkes Provinsi Jawa Tengah. 2006. Pedoman Pelaksanaan Desa Siaga. di Jawa Tengah. Semarang.

Kementerian Kesehatan Republik Indonesia. 2010. Pedoman Umum Desa dan Kelurahan Siaga Aktif. Pusat Promosi Kesehatan. Jakarta.

Mubarak, W.I dan Chayatin, N. 2009. Ilmu Kesehatan Masyarakat $=$ Teori dan Aplikasi.Salemba Medika. Jakarta.
Notoatmojo, S. 2003. Ilmu Kesehatan Masyarakat. Rineka Cipta. Jakarta.

Notoatmojo. 2003. Pendidikan dan Perilaku Kesehatan. Rineka Cipta. Jakarta.

Notoatmojo, S. 2007. Promosi Kesehatan dan Ilmu Perilaku. Rineka Cipta. Jakarta.

Notoatmojo. 2005. Promosi Kesehatan Teori dan Aplikasi .Rineka Cipta. Jakarta.

Surat Edaran Mendagri Nomor : 140 / 1508 / SJ. Pedoman Pelaksanaan Pembentukan Kelompok Kerja Operasional dan Forum Desa dan kelurahan Siaga Aktif. Kemenkes RI dan Kemendagri.

Tri Cahyono, 2014. Pedoman Penulisan Proposal Penelitian dan Karya Tulis Ilmiah / Skripsi ,edisi revisi ketiga. Kemenkes R.I. Potekkes Kemenkes Semarang Jurusan Kesehatan Lingkungan Purwokerto. Purwokerto.

Zaki Mubarok, 2010. Evaluasi Pemberdayaan Masayarakat PNPM Perkotaan, Tesis, Undip. 